Pontifícia Universidade Católica de Minas Gerais (PUC Minas). Doutoranda no Programa de Pósgraduação em Linguística e Língua Portuguesa

\section{O CORDEL E SUAS POSSIBILIDADES NO \\ ENSINO DA LINGUAGEM: FORMAÇÃO HUMANA,
DIVERSIDADE E CULTURA FORMAÇÃO HUMANA,
DIVERSIDADE E CULTURA}

Regina Aparecida de Morais

texto apresenta o estudo sobre como o gênero cordel poderia contribuir para a formação linguística dos estudantes da Educação Básica. Seu objetivo foi refletir sobre a relevância do gênero para a formação do sujeito leitor e escritor. Acredita-se que tais leituras e análises poderão colaborar para a discussão de alguns processos metodológicos (didatização) no ensino de Língua Portuguesa no que tange a formação do sujeito como leitor e escritor.

Palavras-chave: Enunciação. Gênero. Cordel. Didatização. Letramento.

Seria a literatura de cordel um texto ultrapassado, morto e inoportuno para os tempos atuais? Decerto que não. A mídia recentemente fez veicular, no cinema e na tevê, textos como Cordel encantado (telenovela exibida pela tevê Globo em 2012) e o filme, O coronel e o lobisomem. São exemplos de uma hibridização, mescla de gêneros: cordel, novela televisiva e curta-metragem. Tal fenômeno é nomeado por MARCUSCHI (2008) como intergenericidade, quando um gênero se vê imbricado em outro.

Nas regiões nordestinas, encontramos, nessa ou naquela barraca, livretos impressos por meios tecnológicos mais modernos, mas seguindo a moda do cordel. Poderia o cordel se tornar objeto de estudo nas aulas de Língua Portuguesa? A literatura de 
cordel, oriunda da cultura popular nordestina, possui grande valor como um bem cultural imaterial. Logo, justifica-se sua inclusão nos currículos escolares. Nessa perspectiva, os estudos das Artes, da Literatura ou da Língua contribuem para a compreensão desse texto no seio da cultura brasileira. Áreas do conhecimento como a História e a Sociologia, dentre outras, oferecem um olhar específico importante para a formação global de estudantes brasileiros em qualquer nível escolar.

Acreditamos que esse gênero, em geral, desperta o interesse do leitor, logo, mobiliza a curiosidade de estudantes da Educação Básica, bem como de estudantes da Educação de Jovens e Adultos. Por meio do cordel, é possível uma relação dialógica significativa com outros textos. Nesse sentido, procura-se compreender melhor a constituição desse gênero textual a fim de colaborar para a discussão de processos metodológicos no ensino de Língua Portuguesa, para além das habilidades de leitura e de escrita, uma vez que a linguagem constitui o sujeito e leva-o a se compreender, a compreender o mundo em que vive e a posicionar-se nele.

Este artigo reflete sobre a relevância do gênero para a formação do sujeito leitor e escritor. A ação do professor de Língua Portuguesa pode se fazer por diversas metodologias, no entanto, interessa a este estudo discutir o trabalho com gêneros textuais na perspectiva dos projetos de letramento. Diante da intenção acima apresentada, selecionamos como conceitos significativos: gêneros textuais; conteúdo temático, forma composicional e estilo (em especial forma arquitetônica e forma composicional), discurso e interdiscursividade.

Para que o estudo se efetive, foram escolhidos dois textos do gênero cordel, veiculados em diferentes suportes. O primeiro, cuja estrutura se aproxima do original do texto de cordel, é intitulado $O$ romance do pavão misterioso, de João Melquíades Ferreira. Já o outro, Lei Maria da Penha, produzido por Tião Simpatia, é texto impresso por meio de recursos tecnológicos, divulgado também na mídia. Baseando-se nos estudos teóricos demandados e na análise dos dois enunciados acima se pretendeu entender como professores de Língua Portuguesa podem explorar o cordel na formação do aluno, uma vez que esse gênero (bem cultural imaterial) continua sendo produzido, inclusive, como um recurso na busca de conscientização dos brasileiros diante da história não oficial e dos direitos dos cidadãos, como no caso de um dos textos escolhido. 
Em tempos em que a diversidade cultural tem sido um dos eixos temáticos discutidos com muita veemência, os textos analisados se apresentam como elementos que podem possibilitar inclusive essa reflexão. Nesse sentido, acredita-se que as reflexões aqui delineadas contribuem no sentido de se pensar o ensino da língua portuguesa engajado numa perspectiva sociointeracionista, progressista e emancipatória.

Iniciamos os estudos conceituando o termo enunciação (BAKHTIN, 2003). Posteriormente, a partir da ideia apresentada por Bakhtin de que "gêneros textuais são modelos mais ou menos estáveis de textos", serão apresentadas as ideias de Marcuschi (2008) e Brait (2012) sobre os gêneros do discurso. Essa abordagem considerará o gênero textual em diferentes contextos enunciativos: a literatura de cordel no bojo de sua origem e a literatura de cordel produzida/veiculada por meio digital. Algumas publicações de cordel trazem uma narrativa histórica, recheada de feitos heroicos ou marcada politicamente por um viés de denúncia. Elas são publicadas a partir da serigrafia e da xilogravura, que muito as valorizam e, até há bem pouco tempo, eram marcas desse gênero textual.

Como se vê, o cordel saiu das cordas, está presente em textos digitais, viodeográficos, dentre outros. Esse dado instigante diz da presença das Novas Tecnologias de Informação e Comunicação (NTIC's) e a ampliação do acesso a diversas culturas e, consequentemente, a transformação de alguns gêneros textuais. Com essas novas possibilidades há uma democratização da informação e ampliação dos acessos, o que diminui as distâncias, aproxima as culturas e possibilita a efetivação de experiências diversas de multiletramento (COSCARELLI, 2005).

Além do mote apresentado acima, é importante compreender neste estudo o deslocamento da narrativa literária, inerente a esse gênero (às vezes, marcada por questões sociais) para temas sociais (etnia, direitos da mulher, programas de assistência social como o Fome Zero, dentre outros). 


\section{Língua e enunciação: fundamentos para a atuação do professor de linguagem e para os trabalhos com gêneros textuais numa dimensão efetivamente discursiva}

No cenário educacional, muitas vozes se misturam quando professores são chamados a discutir o que é a Língua Portuguesa. O estruturalismo, o funcionalismo e o interacionismo se encontram em práticas diferenciadas. Demarcamos neste trabalho a ideia de língua como interação por considerar que o processo de enunciação estudado a fundo consegue aprofundar a língua em todas as suas dimensões. Por meio dele, é possível analisar os aspectos pragmáticos da prática linguística, suas exigências semânticas e seus construtos gramaticais. Para tanto, iniciemos os trabalhos a partir de um paralelo entre as considerações feitas por Bakhtin (2004) e por Benveniste (1989) quanto ao termo enunciação. Para Bakhtin,

\footnotetext{
a enunciação, compreendida como uma réplica do diálogo social é a unidade de base da língua trata-se do discurso interior (diálogo consigo mesmo) ou exterior. Ela é de natureza social, portanto, ideológica. Ela não existe fora de um contexto social, já que cada locutor tem 'um horizonte social'. Há sempre um locutor, ao menos potencial. O locutor pensa e se exprime para um auditório social especial bem definido. (BAKHTIN, 2004, p. 16)
}

O ensino de Língua Portuguesa deve considerar necessariamente a natureza social e ideológica do discurso. Como afirma o próprio autor, o discurso não existe fora de um contexto social. Logo, entender o caráter enunciativo da linguagem requer compreender essa contextualização linguística, o que significa não estudar o texto isolado da prática discursiva. Ensinar os processos de leitura, de escrita e refletir linguisticamente sobre como eles se organizam requer que as práticas de ensino considerem o caráter social e pragmático da linguagem.

Nesse sentido, iniciemos por Benveniste (1989), para quem a enunciação parte de "um interlocutor como parâmetro das condições necessárias da enunciação (83)”, mas conta também com um alocutário, a quem o discurso é dirigido, que suscita outra enunciação de retorno. "Toda enunciação é, explícita ou implicitamente, uma alocução, ela postula um alocutário" (BENVENISTE, p. 84). Percebamos a presença do dialogismo, quando o autor aponta a exigência de um locutor e de um 
alocutário nos processos comunicativos. Por meio de Bakhtin, observamos que esse dialogismo ultrapassa os limites do tempo e do espaço, garantido aí o fenômeno ao qual chamamos de polifonia discursiva, elemento que acaba por revelar aspectos ideológicos inerentes aos discursos.

De início, o cordel, cantado nas feiras, registrado e publicado em condições bastante precárias evolui para a impressão gráfica e, mais tarde, para a produção midiática. Estudos sobre o referido gênero requerem a identificação de um eu e um tu, os quais, conforme apontado por Benveniste, são sujeitos essenciais para a enunciação. De um lado, o poeta (cordelista), de outro, o leitor (apreciador). Ambos compartilham informações e vivências que possibilitam o entendimento, assim como intenções. Se, de um lado, há como demanda a expressão de uma denúncia ou a socialização de um fato pitoresco, de outro, o interlocutor busca informações ou simplesmente o deleite, o prazer diante da poesia, principalmente em um tempo em que todos são convocados a conhecer e apreciar diferentes estéticas e diferentes culturas.

Desde suas origens na Europa, o cordel apresenta esteticamente a voz das camadas populares. Segundo, atividades poéticas semelhantes se desenvolveram em países como Portugal, Espanha, França, Nicarágua e Argentina desde o século XIX. No Nordeste brasileiro, apresenta-se a peculiaridade de um povo historicamente marcado pela colonização portuguesa, pelas dificuldades financeiras e pelas misérias que the são impostas pelas condições geográficas, pelas baixas produção econômica e, sobretudo pelo peso de uma sociedade capitalista, para a qual não representa grandes potenciais financeiros, logo poucos lucros.

Esses dados são importantes para a compreensão do contexto enunciativo dessa produção, o qual interfere na composição do texto (forma composicional e forma arquitetônica) e permite compreender melhor a inserção dos interlocutores nesse processo. No entanto, cada interlocutor se insere num contexto bem particular, com características muito próprias de sua história, de seu posicionamento no mundo e das próprias circunstâncias que envolvem aquela produção específica.

Outro aspecto importante são as intenções, recorrentes no gênero cordel: comunicar, sensibilizar ou denunciar de maneira poética as dificuldades, amarguras e injustiças vividas pelo povo nordestino ou disseminar histórias interessantes e cheias 
de originalidade que esse grupo escuta ou vive. Obviamente, cada poema é produto de uma enunciação específica, embora se inscreva numa macroestrutura constitutiva desse gênero. Conforme aponta Bakhtin (2003, p. 266), "cada enunciado particular é individual, cada campo de utilização da língua elabora seus tipos relativamente estáveis de enunciados, os quais denominaram gêneros do discurso".

O gênero cordel carrega em si conteúdo, estilo e forma, que se repetem a cada poesia que representa esse grupo de textos. Cada texto de cordel tem sua especificidade, no entanto, nenhum deles é igual, pois cada texto é um texto. "O gênero sempre é e não é o mesmo, sempre é velho e novo ao mesmo tempo [...] O gênero vive do presente, mas sempre recorda o seu passado, o seu começo." (BAKHTIN, 2008, p. 12 apud BRAIT, 2012, p. 371). Fica bem clara a relação dialética existente entre as construções culturais sobre a produção de um texto e seu exercício cotidiano, marcadas pelo contexto, pelas intenções, pelas escolhas feitas pelos interlocutores, dentre outros fatores que contribuirão para que um texto tenha unidade e seja uma unidade em meio a diversos textos do mesmo gênero, mesmo que trate do mesmo tema.

Para Miller (2009, p. 16) "o gênero é uma ação retórica tipificada baseada numa situação retórica recorrente”. Pensemos o cordel como uma ação que interfere na realidade. Tomemos como exemplo um texto de cordel como o escrito por Tião Simpatia, Lei Maria da Penha, cuja enunciação se dá pela necessidade de informar sobre os direitos das mulheres que sofrem a violência doméstica. Vários textos de cordel fizeram sua denúncia, estruturando-se conforme o gênero aqui estudado. Mas cada texto faz uma intervenção social diferenciada. Já o texto Pavão misterioso é um exemplo marcante de uma narrativa contada no sertão nordestino, ficção romântica marcada pela estrutura do texto de cordel. Apresenta uma ação marcada pela fruição, trazendo como tema o amor. Propicia a experiência estética e o entretenimento, mas traz velados alguns elementos temáticos sobre os comportamentos humanos e valores. Nesses dois textos capta-se uma ação argumentativa e, por que não dizer, política (direitos da mulher e relações de poder, que se circunscrevem nas relações de gênero).

A partir dos elementos temáticos diluídos no texto de Melquíades Ferreira, pode-se afirmar que o gênero, considerando esse enunciado (essa materialização) oferece subsídios para a construção de projetos interdisciplinares. Certamente, são 
questões que se inserem no cotidiano dos alunos e podem se constituir como objeto de reflexão e proposições para melhorar a qualidade de vida e de relação entre as pessoas. Como poderia ser descrito o processo enunciativo de cada um desses textos? Como a compreensão desses processos poderia contribuir para as metodologias de ensino de Língua Portuguesa?

Para quem ensina Língua Portuguesa é fundamental a compreensão da enunciação. Mesmo que essas teorias não sejam explicitadas para os alunos, alguns aspectos pedagógicos precisam ser cuidados para que, na mediação da aprendizagem, eles compreendam a importância dos aspectos pragmáticos (contextos de elaboração e recepção, os sujeitos envolvidos, a intencionalidade que envolve a enunciação), os aspectos gramaticais e os aspectos semânticos que se articulam no processamento do texto.

Ao explorar os textos analisados, é importante compreendermos que o cordelista representa o "eu", e o leitor, o "tu". De um lado, no caso do texto Lei Maria da Penha, um cantador que pretende denunciar a violência doméstica, enquanto divulga a criação de uma lei que pode minimizar esse problema, de outro lado, o leitor? No caso, o leitor previsto é a figura feminina, principalmente aquela mulher que sofre agressões por parte de seu companheiro e familiares. Pressupõe-se uma leitora que carece de uma linguagem mais acessível em comparação com a linguagem jurídica. Nesse caso, ressaltamos a pertinência do cordel, que entrelaça a escrita formal à linguagem oral, ocorrendo, assim, uma aproximação entre a leitora e a informação de que existem mecanismos para defender sua integridade física e moral.

O contexto situacional se marca pelo início do século XXI, período próximo da promulgação da lei denominada "Maria da Penha", em tempos em que se discute a questão da diversidade, em especial a questão de gênero. Além disso, é importante destacar o avanço das novas tecnologias de comunicação, que possibilitam a disseminação de informações. As intenções se colocam claras: o entretenimento, a fruição e a tarefa de levar ao conhecimento da população a lei e suas peculiaridades.

De outro lado, Pavão misterioso emerge de um contexto nordestino, cenário propício à criação de textos desse gênero por ser um componente cultural histórico. Ele se origina da necessidade de um poeta (eu) expressar-se esteticamente, direcionando seu texto a um apreciador ( $\mathrm{tu})$ dessa linguagem, 
cujo objetivo claro é provocar a fruição e entreter a população. Numa abordagem social, relativa à questão de gênero, poderia sugerir ao leitor a história de Creuza, que vive presa sob a tutela de um pai (o conde), que a faz prisioneira, restandolhe somente apaixonar-se por um homem, que a toma como objeto de seu amor (desejo) de forma literalmente invasiva, pois invade seus aposentos.

Atividades diversas como a retextualização a partir da troca de interlocutores poderiam contribuir para que o aluno cognitivamente experimentasse os cuidados e as demandas para se escrever tendo em vista diferentes enunciatários. Seria bem diferente se os estudantes elaborassem um texto com os mesmos conteúdos (apresentados nos textos acima), mas que fossem destinados a jovens funqueiros que estudassem no Ensino Fundamental ou a jovens românticas que amam assistir a programas como Malhação. A produção de um novo texto que recolocasse o conteúdo no gênero notícia ou histórias em quadrinhos, assim como diversas outras atividades escolares, possibilitaria o exercício de compreensão da enunciação enquanto um fator importante a ser considerado na escrita e na leitura de textos diversos.

Esses são alguns exemplos de práticas que estão inseridas nas escolas atuais e que são mais proveitosas quando os educadores fazem uma mediação pautada no conhecimento que têm sobre as teorias da enunciação. Ou seja, é importante que o educador compreenda a língua como uma ação sócio-histórica e interacionista, sem perder de vista como os enunciados se constituem gramaticalmente e semanticamente para que se concretizem efetivamente. Essa reflexão aponta para que sigamos adiante, pensando em como o cordel pode contribuir para a formação linguística do aluno ou para além dela, para a sua formação como sujeito de práticas de linguagem, inserido num contexto social como cidadão.

\section{Cordel: conteúdo, forma e estilo: diretrizes para a mediação no ensino da leitura e da escrita?}

Legado da cultura europeia medieval, o cordel se expressa, como outros gêneros da oralidade, por meio do contínuo oralidade/ escrita. Embora seu suporte inicial fosse o livreto impresso, ele era contado e cantado para a população, que poderia comprar um exemplar, nas feiras do Nordeste brasileiro. A intertextualidade, marca de todo processo dialógico, assim 
como constitutiva da interação verbal, marca também o gênero aqui estudado não somente pela heterogeneidade relativa à citação ou à alusão a algum outro texto conhecido na cultura brasileira ou, especificamente nordestina; o cordel traz em si marcas da literatura oral advindas de séculos passados.

\begin{abstract}
Em termos atuais, pode-se dizer que o cordel mantém enquanto narrativa algumas características de origem como a função social educativa, de ensinamento, aconselhamento e não apenas entretenimento ou fruição individual [...] Por outro lado, o cordel, absorveu algumas tendências da modernidade, entre elas a veiculação de informações: alguns fatos do cotidiano passam a constituir, muitas vezes, a sua temática. Além disso, assume também um caráter individual, quando o texto e o leitor estão em um contato direto, quando a leitura é solitária ou silenciosa.

Constitui-se em um gênero intermediário entre a oralidade e a escrita. Faz uma espécie de ponte de passagem entre uma cultura e outra, literária. Por isso, matem algumas pistas da oralidade ao ser transposto para o texto escrito e impresso. (BRANDÃO, 2000, p. 120)
\end{abstract}

Quais são as peculiaridades da literatura de cordel? Aspectos peculiares à enunciação já foram abordados anteriormente. Iniciemos a caracterização pelo seu conteúdo. $\mathrm{O}$ texto de cordel traz como conteúdo polêmicas ou temas próprios da cultura popular, bem como estórias e histórias que se instauram no imaginário popular de forma a gerar-lhe a curiosidade. São temas relacionados à morte, às histórias interessantes centradas em fatos (pequenas narrativas, com personagens originais que se apresentam de forma heroica e, às vezes, pitoresca), às informações com tom noticioso e às narrativas históricas, segundo a compreensão popular. A temática desse gênero ainda aborda a religiosidade, na defesa da moral cristã, "um tanto conservadora em certos aspectos, seja no que se refere aos hábitos, costumes, e, sobretudo, deveres femininos, seja nos comportamentos gerais ligados ao casamento, à moda etc." (BRANDÃO, 2000, p. 124).

Quanto ao estilo, podemos destacar o tom literário, a informalidade que se aproxima da fala, bem como o relativo cuidado na linguagem escrita. Texto ritmado usa ainda de boas metáforas e se marca por escolhas, muitas vezes, particulares, de acordo com a subjetividade de cada escritor. Destaca-se, quanto ao estilo, pela literalidade e pela presença do dizer e 
do fazer característico da linguagem popular, cujo tom é de seriedade, respeito e orgulho do trabalho feito. Muito comum ainda, a apresentação pessoal do poeta, que se apresenta de modo a situar-se no mundo. Ocorre também de, ao final, em muitas poesias, o autor criar um acróstico apresentando seu nome, sua autoria.

Quanto à forma composicional alguns elementos tendem a contribuir para uma composição literária bem marcada: "sextilhas (estrofes de seis versos) com versos setessilábicos com esquema rítmico abcbdb, as quadras (estrofes com quatro versos) e os poemas em dez versos" (BRANDÃO, 2000, p. 122). Textos não muito longos se materializam em suporte de apenas uma folha volante avulsa, o que não é o mais comum, mas se estruturam também em folhetos com 4,8 ou 16 páginas ou em livretos que vão de 24 a 64 páginas. Hoje, porém, muitos são os suportes responsáveis por sua veiculação. Dentre eles, pode ser tomada como exemplos a apresentação em site, em vídeos no Youtube e, conforme cita, em produções radiofônicas.

Embora o texto se apresente numa estrutura narrativa, há uma estratégia argumentativa inserida no discurso. Considerando as tipologias que tecem o texto, é muito comum lidarmos com a predominância da narrativa em alguns textos (Pavão misterioso, por exemplo). Em outros casos, há predominância da exposição ou da argumentação (Lei Maria da Penha). Não asseguramos que num mesmo texto estariam presentes todos os elementos expostos como características desse gênero. No entanto, por meio de suas poesias de cordel, o autor expressa seus sentimentos (pathos), aprecia os fatos, mas opina (logos) enquanto se manifesta oralmente, e muitas vezes, no texto escrito se mostra numa construção de autoridade (ethos) muito peculiar ao gênero. Essa autoridade não é obtida por delegação ou favor político, nem por dom divino, mas da condição de escriba, que pode e sabe escrever, e melhor, de quem sabe escrever poemas e coloca essa poesia a serviço da comunidade: entreter, narrar, opinar, divulgar e/ou informar (MENDES, 2011).

Com relação ao cordel, esse "tom", que nos revela a imagem de si do poeta, é compassado por um ritmo, cujo corpo vocal também nos ajuda reconhecer/ incorporar/experienciar o ethos que o poeta constrói em seu discurso.

[...] Podemos notar que, se relacionarmos um conjunto de elementos internos e externos à situação comunicativa 


\section{altemes \\ ESPUC \\ BELO HORIZONTE - N. $29-2016$}

como, por exemplo, as nossas representações sociais associadas ao ritmo e ao corpo (gestos, expressões, etc.), é possível participarmos desse processo de incorporação da imagem de si que o poeta projeta em seu discurso. (MENDES, 2011, p. 86).

A complexidade da caracterização de um gênero reside, certamente, na dialogicidade como um fenômeno que entrelaça experiências histórico-culturais que ultrapassam o limite do tempo, do espaço, o encontro e o desencontro entre interlocutores que interagem. Por meio desse diálogo, o triângulo: composição, conteúdo temático e estilo se tornam, conforme apontam Brait e Pistori (2012), um reducionismo. Nesse sentido, elas discorrem sobre a inserção dos interlocutores num contexto espacial e temporal, que constitui uma relação marcada socialmente por seus desejos, interesses, valores e intenções. O gênero textual se configura de maneira ativa em meio a esses fatores e representa, muitas vezes, ações que garantem não somente uma comunicação, mas um posicionamento e, por que não dizer, uma intervenção no mundo em que tais interlocutores vivem.

Nesse sentido, o gênero de cordel não apenas comunica, mas informa, conscientiza ou registra dados constitutivos da memória coletiva, verdadeiros bens imateriais, que poderiam ser esquecidos com o passamento de toda uma geração. Dentre eles, seguem lendas, narrativas, verdadeiros documentos de como fatos reais ou fictícios se incorporaram a uma cultura. Destacamos aqui o cordel Lei Maria da Penha e sua missão de informar e conscientizar as mulheres sobre a novidade: a garantia de direitos e de proteção frente à violência doméstica ainda tão presente na sociedade brasileira.

Por outro lado, o texto Pavão misterioso representa o registro de uma história que se tornou forte elemento cultural, numa voz que ecoa na música, por exemplo, do cantor Ednardo, homônima, bem como na última cena da primeira versão da novela Saramandaia, quando um homem sai voando. No entanto, esse diálogo não surge a partir da canção de Ednardo (outro gênero) nem tampouco da novela de Dias Gomes (Saramandaia), mas quantas outras conexões podem ter feito os cordelistas? E os seus leitores? A torre de Rapunzel? As mil e uma noites?

Cabe ainda ressaltar a presença da imagem como recurso inerente ao gênero. A imagem marcada pela arte, no caso a xilogravura, de um lado é um recurso visual que, além de 
enriquecer o texto, alivia a formatação. Por outro, compõe o texto, ampliando sua compreensão, resgatando o imaginário do leitor e, de alguma forma, atuando sobre este, uma vez que a imagem, assim como as metáforas, potencializa a construção de sentido na recepção do texto. A musicalidade é outro elemento que colabora para esse processo, intensificando a noção do ritmo e o envolvimento com o cenário ou o contexto narrado/ cantado no texto. A figura nos remete ao mundo simples, à vida simples e a representações do imaginário popular, explorando a sensibilidade, a imaginação e convidando o leitor para adentrar na ficção, sendo ele analfabeto, dominando a norma-padrão ou aventurando-se pela sua presença naquele texto de cordel que também traz marcas da sua experiência enquanto falante de um grupo social menos privilegiado.

Como as variações de registros se inserem no cordel? Quantas modificações são possíveis em relação aos suportes? Quantos temas são tratados? Quantos diálogos são estabelecidos? O triângulo: conteúdo temático, forma composicional e estilo não consiste numa "receita" de gêneros textuais. A forma composicional não é uma fórmula. O estilo diz de uma variedade infinita para a materialização do texto. Onde reside a linha que separa esses três elementos? Há um contínuo, uma ligação extrema que jamais isola o gênero de sua história, da história dos interlocutores. Mais do que uma composição, uma estrutura é construída no imaginário coletivo das pessoas, pautada por elementos que dizem da materialização e da recorrência de escolhas e formatação.

Essa forma ultrapassa a estruturação do gênero como um enunciado, ultrapassa a própria enunciação, embora não se separe deles. Há uma forma arquitetônica que desenha o gênero para além da situação comunicativa $\mathrm{X}$ ou $\mathrm{Y}$, mas que nela também se encontra. Essa forma arquitetônica não se resume na forma composicional; ela contém a forma composicional, mas ultrapassa essa forma, ela representa essa construção linguística, que é também cultural, construindo-se na cultura e ultrapassando-a.

Tal peculiaridade pode ser analisada no cordel a partir de sua história. O gênero não é estável, mas lida com algumas peculiaridades que permitem ao ser humano acessar no seu universo cultural uma referência (modelo mais ou menos estável) de texto. Nem o leitor nem o cordelista misturariam a novela Saramandaia ou a canção Pavão misterioso com um texto de cordel, pois nenhum deles se enquadra no padrão social e culturalmente esperado como cordel. 


\section{alteras \\ ESPUC \\ BELO HORIZONTE - N. $29-2016$}

Nesse sentido, um trabalho pedagógico centrado apenas nas regras do texto de cordel, em sua materialização, reduz toda a possibilidade de formação linguística e humana ao ensino de normas, se ele explora apenas os processos enunciativos sem considerar o enunciado, ele está sendo reducionista, por viabilizar o ensino dos aspectos pragmáticos. Se esse ensino se prende apenas aos significados, sem considerar os outros aspectos da forma arquitetônica, dificilmente os sentidos construídos darão conta do significado da linguagem do cordel para a cultura nordestina, e obviamente, para a brasileira.

Entender os interlocutores idealizados como produtores e receptores do cordel é importante, assim como reconhecer que esse texto é espaço de interdiscurso, o que marca também o ritmo, a métrica, a musicalidade da poesia de cordel; todos esses aspectos nos permitem um pouco mais compreender a complexidade desse gênero textual. A intertextualidade se acena como uma estratégia de ensino que pode contribuir para a formação dos estudantes. Perceber as vozes dos textos inerentes ao texto de cordel, identificar e analisar outros textos associados ao tema, reconstruir narrativas pode contribuir para a ampliação de um domínio linguístico que ultrapasse os conhecimentos das regras gramaticais, mas que atue na habilidade de usá-las, conduzindo em favor das suas necessidades enquanto falante, escritor, leitor e ouvinte de um texto.

Compreender a inserção de um texto no mundo em que vivemos pode ajudar-nos a nos inserirmos, nesse mundo, como sujeitos. O real letramento possibilita não o domínio das letras, mas o domínio desse sujeito diante da sociedade, uma vez que é senhor de seu discurso e sabe por que e para que quer trabalhar. Nesse conjunto se insere a significação e, obviamente, a estruturação formal de um texto. No entanto, esses atos são decorrentes da compreensão desse gênero, que só será interessante se de fato a interação ocorrer. Dizer da forma arquitetônica é dizer da "identidade de um gênero", de sua plasticidade segundo os tempos, os sujeitos e as intenções que cada um carrega.

Essas considerações contribuem para se pensar o ensino do cordel na sala de aula. A enunciação deve ser elemento explorado na recepção do texto escolhido como objeto de análise. A produção escrita realizada pelos alunos deve considerar os aspectos pragmáticos. A contextualização possibilita visão mais significativa, pois o texto no ambiente escolar é visto de forma idealizada e artificial. Algumas questões de estilo recorrem 
enquanto aspecto constituinte do gênero e enquanto aspecto representativo da escolha e do gosto de quem escreve.

Entender o cordel requer os estudos e reflexões sobre verso e prosa, estrofes, elementos formais fundamentais na construção desse texto. Quanto à métrica, poderia ser tomada informação, pois o estudo da métrica e da rima, de uma forma muito rígida pode não ser interessante para todos os alunos. Já a relação entre escrita e oralidade, entre norma-padrão e norma-popular é elemento significativo, que se constitui como conteúdo importante para a construção desse gênero e para o desenvolvimento de habilidades importantes para o bom desempenho linguístico. As metáforas também se constituem como importante estratégia de estudo, uma vez que enriquecem o texto de cordel, assim como os textos orais e escritos aos quais estamos expostos cotidianamente. É interessante ainda refletir sobre os constantes desvios ortográficos, sua significação no texto e a prática de revisão nos textos em geral, com o cuidado para não criar uma relação comparativa, que gere menosprezo por essas marcas na textualização do cordel. Quanto aos aspectos que refletem a escolha do autor, também deve ser explorada, como reflexão sobre a autoria, a liberdade de expressão e a valorização das opções de estilo que cada autor tem ao dizer/escrever.

Ao considerar a textualização, cada autor organiza o vocabulário, as estruturas frasais, a conexões, assim como administra as próprias exigências de concordância e de regência, dentre outros fatores que a tessitura vai impondo no processamento do texto. Esses também são objetos que contribuem para a compreensão da língua e das estratégias que garantem ao sujeito o domínio das competências linguísticas. Embora restritas, essas últimas considerações buscam refletir sobre a atuação do professor diante do gênero cordel. Entretanto, as atividades elaboradas e desenvolvidas de maneira fragmentada não permitem uma ação estruturada, cujo resultado é o desenvolvimento dos alunos a médio e longo prazos. Por isso, discutiremos a seguir possibilidade de planificação do trabalho com gêneros textuais por meio de um projeto de letramento.

\section{Como pensar a entrada do gênero cordel na sala de aula?}

Para discutirmos as possíveis atividades relacionadas ao trabalho escolar com esse gênero na escola, é fundamental que pensemos 
mais profundamente sobre estudos já realizados sobre o fazer pedagógico na aula de língua. Para tanto, exploraremos o projeto de letramento como uma possível planificação para o trabalho com cordel. Por que essa escolha? Efetivamente, os gêneros textuais primários ou secundários estão sempre em evidência nos estudos escolares, no entanto nem sempre se desloca das velhas práticas para um modelo de fato capaz de atender a complexidade que essas mudanças requerem. Acreditamos que o projeto de letramento se configura como uma proposta de trabalho que possibilita esse deslocamento e envolve de maneira mais efetiva o estudante no processo de ensino, além de possibilitar a educadores e educandos construir novas perspectivas para o ensino da linguagem.

\section{Projeto de letramento}

O projeto de letramento parte do princípio de que os planejamentos educacionais precisam ser revistos e retoma as contribuições de John Dewey, que aponta, assim como Paulo Freire e Celestine Freinet (apud KLEIMAN; CENICEROS; TINOCO, 2013), a importância de que a escola reveja suas perspectivas de trabalho e garanta uma educação como processo social em que as experiências dos estudantes e das comunidades sejam significativas.

Nos últimos anos, experiências com projetos têm crescido no cenário educacional brasileiro. A experiência com a pedagogia de projetos nas últimas décadas tem provocado reflexões interessantes, representado práticas interessantes e positivas na construção de uma escola em que alunos e professores se colocam como atores, ou melhor, sujeitos no processo de construção do conhecimento. Trata-se de uma proposta distante da perspectiva tecnicista colocada muitas vezes de forma silenciosa no fazer educacional de vários professores em diversas escolas.

Nessa perspectiva, a ação pedagógica traz em si um caráter reflexivo pautado pela interação. Tal processo requer dos sujeitos a sua inserção nas situações comunicativas reais. Por meio delas é que os homens desenvolvem práticas de letramento ou, melhor dizendo, multiletramentos.

Letramentos ou múltiplos letramentos, termos que se equivalem, é um conceito caro aos novos estudos do letramento que traz em sua acepção a ênfase na natureza social do letramento e no caráter múltiplo das 


\section{alemos \\ ESPUC \\ BELO HORIZONTE - N. $29-2016$}

práticas letradas (STREET, 2014). Nessa abordagem, letramento como prática social afigura-se como tese central. Isso, conforme Street $(1984,2014)$, Barton e Hamilton (1998), implica compreendê-lo como construções sociais e históricas, embebidas de crenças, valores e saberes, inscritas em relações de poder de diferentes ordens, as quais diferem no tempo e espaço, de uma cultura para outra, de um domínio social para outro, de um grupo social para outro (SILVA; ASSIS; BARLETT, 2013, 11).

Observemos que o conceito de letramento dialoga com a perspectiva de formação apontada por Freire (1995), na medida em que esses processos dizem de um posicionamento dos sujeitos envolvidos na interação verbal, bem como nos processo educacionais. Tal posicionamento requer uma capacidade de leitura que ultrapasse as palavras e as aparências que são tecidas no texto por meio de ideologias e formações discursivas. Logo, ler requer uma compreensão de mundo que ultrapassa as salas de aula e os muros da escola, mas relaciona-se intimamente com a cosmovisão que cada um vai construindo a partir de suas vivências e de suas leituras.

Já por projeto de letramento, entende-se

\begin{abstract}
um conjunto de atividades de um interesse real na vida dos alunos e cuja realização envolve o uso da escrita, isto é, a leitura de textos que de fato circulam na sociedade e a produção de textos que serão lidos, em um trabalho coletivo de alunos e professor, cada um segundo sua capacidade. O projeto de letramento é uma prática social em que a escrita é utilizada para atingir um outro fim, que vai além da mera aprendizagem da escrita (aprendizagem dos aspectos formais apenas), transformando objetivos circulares como " escrever para aprender" e "ler para aprender" em ler e escrever para compreender aquilo que for relevante para o desenvolvimento e a realização do projeto (KLEIMAN; CENICEROS; TINOCO, 2013, p. 72).
\end{abstract}

Mas quem decide o que é do interesse do aluno? Essa proposta então requer uma revisão das relações de poder no âmbito da escola. O diálogo é o ponto de partida, pois o interesse do aluno é o ponto de partida para a organização dos projetos. As atividades linguísticas estão, portanto, inseridas em práticas concretas de linguagem e de ações sociais. Os textos estudados são demandas das ações desencadeadas pelo projeto, logo se circunscrevem no projeto enquanto práticas reais de 
comunicação. Ler e escrever deixam de ser tarefas escolares e relacionam-se com o engajamento social, em que os sujeitos buscam contribuir para mudar a sua realidade. "A implicação disso é ressignificação conceitual importante: ler e escrever são práticas circunscritas à esfera escolar. Lemos e escrevemos para agir no (e sobre o) mundo" (KLEIMAN; CENICEROS; TINOCO, 2013, p. 74).

O projeto de letramento se distancia das práticas conteudistas, que são frutos de uma escola conservadora, centrada no processo de repetição de informações, que gerava/gera a heteronomia, contribuindo pouco para a formação de leitores proficientes e escritores habilidosos. No entanto, tememos o risco de excesso de pragmatismos. Algumas teorias iluminam nessas práticas e nem sempre estão ligadas tão diretamente ao texto.

Por exemplo, compreender o gênero cordel e suas peculiaridades diz respeito diretamente ao domínio de alguns conteúdos que dificilmente necessitarão de um estudo sobre eles, como compreender o que são versos e estrofes, entender o que é um acróstico, etc. Estudos sobre a origem do cordel podem não aparecer como uma necessidade dentro do contexto de ação do projeto, nem mesmo dentro das situações comunicativas que ele envolve. Mas aprofundar em tais elementos pode levar o homem a compreender melhor a tessitura da poesia de cordel, bem como compreender melhor aspectos históricos da sociedade e do próprio gênero. Sem dúvida, o conteudismo não gera uma aprendizagem significativa, mas o pragmatismo minimiza as relações de ensino/aprendizagem. Não estamos afirmando que esse risco seja uma característica do projeto de letramento.

De fato, a proposta é bastante aberta, e os sujeitos definirão o grau de profundidade dos estudos. No entanto, caso o grupo tenha uma visão simplista dos conceitos, práticas e vivências realizadas, a metodologia requererá do mediador uma preparação e uma capacidade dialógica muito grande para que ocorram aprendizagens significativas e com a profundidade necessária, sem que este abuse do seu poder enquanto liderança do grupo, sem que seja autoritário ou desrespeitoso. Por outro lado, a construção de sentido e a curiosidade compõem a diversidade e a heterogeneidade tão presentes na sala de aula.

Tomando o cordel como objeto de estudo, é interessante pensar que seu lugar social pode ser reconhecido como espaço de fruição. Nesse sentido, uma possibilidade é que o trabalho 
com esse gênero se resuma a uma experiência estética. Uma segunda possibilidade é que o texto se torne mero pretexto para estudos dos temas tratados ou motivador para debates. Há, por fim a possibilidade de uma exploração do gênero, considerando o processo de enunciação e sua materialização. Nesse último caso, certamente, no cordel seriam reconhecidos outros papéis sociais, outras intenções e outros usos, como ocorrem no texto Lei Maria da Penha, em que o texto chega à hibridização (MARCUSCHI, 2008) por desempenhar sem prejuízos o papel de uma cartilha popular com o objetivo de conscientizar os cidadãos, em especial, as cidadãs, sobre os direitos da mulher e de informar e orientar minimamente sobre os recursos legais que garantem a proteção e a dignidade da mulher diante da violência doméstica.

Não seria possível, dada a riqueza que os projetos de letramento propiciam, estipular esse ou aquele uso do texto de cordel, uma vez que se trata de uma prática pedagógica que se orienta pela participação dos sujeitos envolvidos, sendo que a variedade de propostas, o aprofundamento dos estudos, as ações estão relacionados a essa participação, bem como aos eventos que cada planificação das ações pode trazer enquanto ações sociais - espaço concreto de aprendizagem e atuação na transformação de cada sujeito, aluno ou professor - e do grupo, da escola das comunidade ou da sociedade em geral.

O ensino da língua portuguesa em sua plenitude colabora para a construção da emancipação dos sujeitos, o que certamente não se reduz ao trabalho da língua portuguesa (SOARES, 2002) nem tampouco à escola, que se configura apenas como uma das instituições sociais que atuam na educação nas sociedades em geral. No entanto, é papel da instituição e dos professores contribuir para essa emancipação. O projeto de letramento atua no sentido de construir coletivamente processos emancipatórios possíveis dentro da cultura escolar, ainda muito marcada pela reprodutivismo. Embora o ensino de Língua Portuguesa, inserido no projeto de letramento, também se direcione para esse fim, ele é componente de uma construção maior: a formação integral do aluno.

Sem dúvida, o trabalho com o gênero cordel pode se inserir num projeto de letramento, mas sua realização e os procedimentos didáticos ocorrerão conforme a proposta de trabalho construída no coletivo de educadores e educandos. Constitui um material interessante na construção de práticas ínter e transdisciplinares como meio de formação integral dos 
sujeitos. Várias possibilidades se apresentam como espaço de formação humana e de formação linguística. Não haveria, portanto, sentido em falar de modelos engessados de trabalho, pois não haveria coerência com a metodologia apresentada. No entanto, é interessante discorrer sobre a intertextualidade como aspecto dialógico importante para a formação linguística, sobre a autoria dos sujeitos que são cidadãos, cujas histórias se aproximam principalmente das dos alunos de classes populares, sobre o continuum entre oralidade e escrita, sobre o papel social de muitos textos que dizem diretamente das demandas sociais no cotidiano das pessoas, dentre outros aspectos.

\section{Conclusão}

O estudo do cordel, embora tenha sido apresentado numa perspectiva, aparentemente deôntica, configura-se como uma demanda para a formação do povo brasileiro, dada a riqueza que o texto representa inicialmente, por nascer da vida de pessoas simples, das classes populares, podendo romper com uma visão social de escrita em que somente são reconhecidos como autores sujeitos escolarizados e empoderados para essa ação. Por muitos anos, a escola deixou o sujeito num lugar de espectador dos processos de produção escrita, por acreditar numa visão linguística reducionista, que coincide com práticas autoritárias que reservava o mundo da escrita a uma pequena elite.

Hoje a democratização da informação possibilitada pelas NTIC's contribui significativamente para a mudança desse quadro. No entanto, historicamente, sujeitos da cultura ocidental, representados pelos nossos colonizadores e, em especial, os nordestinos, como legado, se impuseram ao longo dos anos, suplantando a negação desse espaço numa ação concreta, que se materializa no texto de cordel, que representa a literatura, a filosofia e a política que esses indivíduos constroem em seus entornos. Culturalmente esse grupo se impõe e deixa a cada dia, na simplicidade de seu cotidiano, um patrimônio. Uma forma de valorização desse material é a disseminação e a reflexão sobre como o cordel se organiza, sobre como utilizá-lo em suas pequenas "lutas" como denúncia, como expressão estética, e, mesmo como material para a conscientização popular.

Não é apropriado para nós traçarmos propostas ou modelos de trabalho com a literatura de cordel. No entanto, cremos que, após um trabalho significativo sobre gêneros textuais, é 
produtivo pensar algumas das categorias numa perspectiva didática. $O$ cordel foi escolhido enquanto um gênero na perspectiva de compreender quais seriam suas possibilidades pedagógicas para o ensino da língua, considerando as três propostas de didatização dos gêneros textuais apontadas acima: sequência didática, projetos de letramento e projeto didático de gêneros.

As três perspectivas se apresentam como alternativas para um trabalho capaz de compreender as experiências do homem com a língua de um ponto de vista mais profundo e científico ao considerar os avanços realizados pela Linguística em geral. Não há contradições, embora haja diferenças nas três propostas. Alguns poderiam compreender a proposta de Letramento como mais adequada ao Ensino Médio e à EJA (Educação de Jovens e Adultos), dado o grau de autonomia que é exigido dos estudantes e professores. No entanto, questionamos se a autonomia não pode ser construída no diálogo, na interação e no rigor dos compromissos firmados desde a infância. Já a ideia do projeto didático de gênero apresenta avanços em relação à sequência didática nesse item, sem perder a sistematização naquilo que é próprio do processamento do texto e de sua inserção no mundo.

Mas seria pertinente a todas essas propostas o trabalho com o gênero cordel? Ao final do texto, consideramos que, segundo a peculiaridade de cada proposta, é possível explorar sem superficialização o gênero. No entanto, penso que sua exploração não deve se restringir à ideia de leitura e escrita como habilidades pontuais, mas, como apontamos acima, na perspectiva de contribuir para o letramento de nossa sociedade numa perspectiva multicultural e engajada com as demandas de nosso tempo como, por exemplo, respeito à diversidade, democratização da informação e acesso aos direitos sociais.

Do ponto de vista linguístico, torna-se importante destacar que a ação do educador/professor de língua deve ser guiada pela compreensão desta enquanto ação sociodiscursiva, o que requer a compreensão do gênero de uma maneira mais viva e profunda. $\mathrm{O}$ texto materializado é o produto de um processo que incorpora um mundo real, de pessoas reais, com histórias e objetivos, nem sempre conscientes, nem sempre compartilhados, nem sempre éticos e sensíveis, mas humanos.

Isso requer "descongelar" os construtos teóricos e ressignificálos numa dimensão menos idealizada e mais pragmática. Requer 
também menos artificialização e mais realização; assim, um avanço nas três propostas demandaria a realização de eventos comunicativos. Estudar o cordel significa ler cordel, pensar cordel e escrever cordel. As atividades didáticas são estratégias que levam ao entendimento e à construção do conhecimento, mas o texto precisa se configurar como um evento linguístico que sairá dos cadernos e entrará na pauta de leitura de outros sujeitos: a organização de jornais, a construção de uma história em quadrinhos, a organização de um blog. No caso do cordel, pode ser interessante publicizar os cordéis produzidos pelos alunos num varal junto a uma feira local. Esse varal pode ser estendido no pátio da escola ou divulgado num blog para sua socialização, inclusive com aulas destinadas a sua leitura.

Aspectos como a intertextualidade, a história, o processo de enunciação e as peculiaridades do gênero - os temas, os versos, a rima, os interlocutores, as intenções, as estratégias, as marcas de oralidade e da língua popular - os suportes, as diferentes abordagens e construções linguísticas e estéticas, a ilustração são como um banco de possibilidades na elaboração de atividades que ampliam não somente as habilidades cognitivas, mas também os valores éticos, o domínio de conteúdos construídos pela ciência em diálogo com a cultura popular.

Que atividades seriam essas? Estão prontas, fechadas? Cabe a cada professor em condição de produtor do conhecimento pesquisar, selecionar e adaptar, elaborar - mas atuar como sujeito que interage e se compromete com esse processo, com esses sujeitos. Observa-se, pelos estudos, que esse gênero possibilita atividades de leitura, de reflexões linguísticas e de produção escrita e oral. Por meio dele, narrar, argumentar, expor sentimentos são caminhos que levam a uma reflexão sobre o texto, sobre a sociedade e sobre a vida.

Gostaríamos ainda de acreditar que a intervenção pedagógica para o trabalho com outros gêneros pudesse, na ação de qualquer professor brasileiro, provocar interação efetiva entre os sujeitos envolvidos. Nesse sentido, essa reflexão propõe desconstruir a ideia de gênero, que muitas vezes movimenta a ação do professor, por meio do texto, tomado como objeto. O próximo passo é a construção da ideia de que o texto são vozes que são processadas, de forma complexa, antes de sua materialização e de que essas vozes continuam ecoando em outras enunciações, cujos produtos são novos textos. Esperamos ainda que, por meio de uma leitura dialógica, os homens possam se interpretar melhor, compreender melhor suas necessidades, 
as necessidades do outro e, por fim, as necessidades que se impõem para uma vida social pautada na ética, na alteridade e na vida em comunidade. Trata-se da esperança de que a ação do professor, assim como a educação formal, possa cumprir a função de formar e transformar sujeitos rumo à emancipação.

\section{ABSTRACT}

The paper presents the study of how the gender cordel (string) could contribute to language training for students of basic education. Their goal was to reflect on the relevance of gender to the formation of the individual reader and writer. It is believed that such readings and analysis can contribute to the discussion of some methodological processes (didactization) in portuguese language teaching regarding the formation of the subject as a reader and writer.

Keywords: Enunciation. Cordel. Didactization. Genre. Literacy.

\section{REFERÊNCIAS}

BAKHTIN, Mikhail M. Estética da Criação Verbal. 4. ed. Tradução de Paulo Bezerra. São Paulo: Martins Fontes, 2003.

BENVENISTE, Émile. O aparelho formal da enunciação. In: BENVENISTE, Émile. Problemas de Linguística Geral II. São Paulo: Pontes, 1989. p. 81-90.

BRAIT, Beth; PISTORI, Maria Helena Cruz (Org.). A produtividade do conceito de gênero em Bakhtin e o Círculo. Alfa, Revista de Linguística (UNESP, Online), São Paulo, v. 56, n. 2, p. 371-401, 2012. Disponível em: <http://seer.fclar. unesp.br/alfa/article/viewFile/5531/4343>. Acesso em: 14 jul. 2015.

BRANDÃO, Helena Nagamine. Gêneros do discurso na escola: mito, conto cordel, discurso político e divulgação científica. São Paulo: Cortez, 2000.

BRONCKART, Jean-Paul. Visão de conjunto. In: BRONCKART, Jean Paul. Atividade de linguagem, textos e discursos: por um interacionismo sócio-discursivo. Tradução de Anna Rachel Machado e Péricles Cunha. São Paulo: EDUC, 1999. p. 113$135 ; 157-181$. 
COSCARELLI, Carla Viana; RIBEIRO, Ana Elisa. Letramento digital: aspectos sociais e possibilidades pedagógicas. Belo Horizonte: CEALE; Autêntica, 2005.

FREIRE, Paulo. A importância do ato de ler. São Paulo: Cortez, 1995.

GUIMARÃES, Ana Maria Mattos; KERSCH, Dorotea Frank. Por uma formação continuada cooperativa: o desenvolvimento do processo educativo de leitura e produção textual escrita no Ensino Fundamental no contexto de um município brasileiro, 2012. Disponível em: <http://www.cchla.ufrn.br/visiget/ pgs/pt/anais/Artigos/Dorotea $\% 20$ Frank $\% 20$ Kersch $\% 20$ \%E2\%80\%93\%20UNISINOS\%20e\%20Ana\%20Maria\%20 Mattos\%20Guimar\%C3\%A3es\% 20\%E2\% 80\%93\%20 UNISINOS.pdf>. Acesso em: 14 jul. 2015.

GUIMARÃES, Ana Maria Mattos; KERSCH, Dorotea Frank. Explorando os projetos didáticos de gêneros. In: GUIMARÃES, Ana Maria Mattos; KERSCH, Dorotea Frank. Caminhos da construção: projetos pedagógicos de gênero nos domínios do argumentar. Campinas, SP: Mercado das Letras, 2014. p. 1737.

MENDES, Simone. Entre o factual e o ficcional: a construção (pré)discursiva do ethos em um cordel de acontecimento. Entrepalavras, Fortaleza, ano 2, v. 2, n. esp., p. 83-97, jan./jul. 2012.

MILLER, Carolyn R. Estudo sobre gênero textual, agência e tecnologia. In: DIONÍSIO, Angela Paiva; HOFFNAGEL, Judith Chambliss (Org.). Recife: Ed. Universitária UFPE, 2009, p. 19-58.

KLEIMAN, Angela B.; CENICEROS, Rosana Cunha; TINOCO, Glícia Azevedo. Projetos de letramento no ensino médio. In: BUNZEN, Clécio; MENDONÇA, Márcia. Múltiplas linguagens para o ensino médio. São Paulo: Parábola, 2012. p. 60-83.

SILVA, Jane Quintiliano Guimarães; ASSIS, Juliana Alves; BARTLETT, Lesley. Letramento e identidade: questões em estudo. Scripta, Belo Horizonte, v. 17, n. 32, p. 9-22, $1^{\circ}$ sem. 2013.

SIMPATIA, Tião. Lei Maria da Penha em cordel. Fortaleza (CE): Armazém da Cultura. 


\section{alteras

SOARES, Magda, Linguagem e escola: uma perspectiva social. 17. ed. São Paulo: Ática, 2002. p. 95.

CORDEL ENCANTADO. Direção: Amora Mautner e Ricardo Waddington. Criação: Dica Rachid e Thelma Guedes. Rede Globo de Televisão. 1081i HDTV, 2011. Son., color.

O LOBISOMEM e o coronel (Animação). Produção: Elvis K. Figueiredo e Ítalo Cajueiro. Distrito Federal: Brasília, 2002. son., color., $10 \mathrm{~min}$.

Recebimento: 21/11/2016

Aceite: 15/12/2016 